\title{
Configurações da gestão escolar nos sistemas municipais e estadual em Pernambuco
}

\author{
Luiz Alberto Ribeiro Rodrigues ${ }^{I}$
}

Resumo: O presente artigo apresenta resultado de pesquisa realizada em escolas das redes municipais e estaduais, utilizando-se procedimentos de observação baseados nos princípios da pesquisa participante, princípios do método de análise de política pública, com o objetivo de caracterizar a concepção e práticas da gestão escolar na escola pública. Procurou-se analisar a influência das atuais políticas educacionais na cultura de gestão educacional e problematizar as práticas existentes, frente aos referenciais da ciência da educação. Foram analisados ainda seis diferentes aspectos pertinentes à gestão educacional, conforme a seguir: teoria da administração presentes na gestão escolar; dimensões da realidade que ocupam a gestão; natureza predominante da liderança escolar; e estratégias de gestão.

Palavras chaves: Gestão Escolar, Participação, Autonomia.

\section{Settings school management in municipal and state systems in Pernambuco}

\begin{abstract}
The article presents Gift result of research conducted in the municipal and state schools, using observation procedure based on the principles of participatory research, with the objective of characterizing the design and practices of school management in public schools. He tried to analyze the influence of current educational policies in educational management culture and question existing practices, compared to education science benchmarks. They were also analyzed six different aspects related to educational management, as follows: management theory present in school management; dimensions of reality that occupy management; predominant nature of school leadership; and management strategies.
\end{abstract}

Key words: school management, participation, autonomy.

Artigo recebido em 15/03/2016 e aprovado em 03/04/2016. 


\title{
CONFIGURAÇÕES DA GESTÃO ESCOLAR NOS SISTEMAS MUNICIPAIS E ESTADUAL EM PERNAMBUCO
}

\author{
LUIZ ALBERTO RIBEIRO RODRIGUES
}

\section{Introdução}

O conceito de gestão democrática no âmbito da escola pública tem se tornado um discurso presente no Brasil, essencialmente caracterizado como um esforço coordenado e coletivo, como ideia de trabalho associativo realizado por pessoas autônomas, que analisam situações e tomam decisões sobre a escola, com base no querer coletivo. Essa modalidade de gestão é definida pelo preceito legal posto na Lei de Diretrizes e Bases da Educação Nacional $(\mathrm{LDBN})^{\mathrm{II}}$, que no seu Art. $14^{\circ}$, delega aos sistemas de ensino a definição de normas para por em prática os princípios da gestão democrática do ensino público na educação básica, de acordo com as suas peculiaridades. A referida lei indica o princípio da participação, como fundamental para garantia da democracia a ser exercida pelos profissionais da educação, na elaboração do projeto político pedagógico da escola e pela comunidade escolar e local, em conselhos escolares ou equivalentes. Nesse contexto, compreende-se que, a participação tem relação direta com a capacidade política de mobilizar pessoas, ideias, conhecimento e difusão de direitos e deveres, processo efetivo de exercício de poder, que traduz a capacidade individual ou coletiva de influenciar as decisões sobre o processo político pedagógico da instituição escolar.

Além da participação, outro princípio de igual importância é a autonomia, previsto no Art. $15^{\circ}$, quando afirma que, os sistemas de ensino assegurarão às unidades escolares públicas de educação básica que os integram progressivos graus de autonomia pedagógica e administrativa e de gestão financeira, observadas as normas gerais de direito financeiro público.

Tudo isso é reafirmado no Plano Nacional de Educação (2014 -2024), quando estabelece na meta 19, a garantia de leis específicas em todos os níveis do estado, para a efetivação da gestão democrática na educação básica e superior pública. Assegurado entre outros as decisões em colegiados e a participação das comunidades escolar e acadêmica na escolha para a direção.

Meta 19. Garantir, em leis específicas aprovadas no âmbito da União, dos estados, do Distrito Federal e dos municípios, a efetivação da gestão democrática na educação básica e superior pública, informada pela prevalência de decisões colegiadas nos órgãos dos sistemas de ensino e nas instituições de educação, e forma de acesso às funções de direção que conjuguem mérito e desempenho à participação das comunidades escolar e acadêmica, observada a autonomia federativa e das universidades. ${ }^{\text {III }}$

Fundamenta-se assim a gestão escolar democrática em dois importantes princípios políticos: a participação como categoria política balizadora do processo de decisão colegiada, 


\section{CONFIGURAÇÕES DA GESTÃO ESCOLAR NOS SISTEMAS MUNICIPAIS E ESTADUAL EM PERNAMBUCO}

\section{LUIZ ALBERTO RIBEIRO RODRIGUES}

e a autonomia, no sentido da capacidade a ser desenvolvida na direção da autodeterminação, do governar-se, do dirigir-se por si mesmo na tomada de decisões colegiadas em torno da organização e do planejamento do trabalho escolar, da liderança no fazer pedagógico, diferentemente dos processos produtivos convencionais.

É nesse sentido que a gestão escolar democrática se caracteriza como um processo de organização do processo educativo em que "[...] o administrador escolar é um educador que se preocupa com a organização do trabalho escolar, como um coordenador de homens independentes, capazes de decidir juntos sua ação.",IV

É um processo de gestão diferente das outras organizações? Sim! A gestão da escola difere das demais instituições em aspectos centrais, tais como o seu objeto, os objetivos e portanto na especificidade do processo como um todo. Na prática a gestão escolar se realiza a partir de funções que espelha um processo próprio da organização escolar, podendo-se destacar: a) Motivar e mobilizar equipes b) Elaborar o Projeto Política Pedagógico; c) Provocar a participação da comunidade nas decisões; d) Exercer a autonomia que a lei lhe confere; e) Organizar o trabalho com estudantes e os professores; f) Lidar com os resultados da aprendizagem; g) Estimular e criar condições para capacitar os profissionais.

Para além disso, deve-se considerar que, na atual conjuntura, a gestão escolar tem sido objeto de muitas políticas públicas, na sua essência, intervencionistas, que apontam para mudanças nas funções, e por vezes ferem a autonomia e influenciam diretamente o modo possível de operacionalizar a gestão escolar em cada rede de ensino. Sobre essa questão indicamos a leitura de o estudo sobre o Plano de Desenvolvimento da Escola, PDE e sua repercussão nos rumos da gestão escolar. ${ }^{\mathrm{V}}$

Essas políticas têm aprofundado estratégias de controle e regulação numa perspectiva neoliberal e aparecem, sobretudo, a partir da década de 1990, dentro de um processo que se tem chamado de reforma na educação no Brasil, ou mesmo reformas administrativas, em que foram difundidas políticas de flexibilidade, com "orientações administrativas cujo referencial é a realidade desenvolvida em empresas privadas. Na gestão da educação pública, os modelos fundamentados na flexibilidade administrativa podem ser percebidos na desregulamentação de serviços descentralização dos recursos, posicionando a escola como núcleo do sistema."VI As políticas advindas desse movimento provocam uma ressignificação ou interpretação dos conceitos da gestão democrática como menciona a autora, "a partir daí, o que se assiste é uma tentativa de interpretação do conteúdo deste dispositivo, o que possibilita que diferentes políticas se efetivem por sob o mesmo manto da gestão democrática". VII

\section{Configuração da gestão democrática na escola pública em Pernambuco}

Mas, como muito já se disse, a democracia é uma obra cada vez mais inacabada, processo que merece constante avaliação. É nesse sentido que este estudo pretende caracterizar a concepção e práticas de gestão escolar presentes nos sistemas municipais e 


\section{CONFIGURAÇÕES DA GESTÃO ESCOLAR NOS SISTEMAS MUNICIPAIS E ESTADUAL EM PERNAMBUCO}

\section{LUIZ ALBERTO RIBEIRO RODRIGUES}

estadual de educação em Pernambuco. De modo específico, procurou-se identificar concepções da teoria da administração presente na prática da gestão escolar, compreender as dimensões técnicas e políticas presentes na atuação da gestão escolar, analisar a relação entre estratégias do atual modo de gestão e o princípio político da participação, e, por fim, problematizar as estratégias do atual modo de gestão em relação ao princípio político/pedagógico da autonomia.

Utilizando-se de princípios da pesquisa participante, tendo sido os dados coletados por meio de observação realizada em escolas públicas municipais e estaduais, entre os meses de março a maio de 2015, por professores ou técnicos que trabalham em cada uma das escolas pesquisadas, estudantes das seguintes disciplinas: Gestão Escolar (curso de pedagogia) e Processos de Gestão da Educação Básica, (disciplina optativa do Programa de Mestrado Profissional de Educação), ambos da Universidade de Pernambuco - Campus Mata Norte.

Assim sendo, os dados de observação foram levantados em 26 escolas públicas, sendo $18(69 \%)$ dessas, do ensino fundamental das redes municipais localizadas na Zona da Mata Norte de Pernambuco, e 08 (30,7\%), do ensino fundamental e médio da rede estadual, 50\% localizadas na Mata Norte, $25 \%$ na Região Metropolitana do Recife e $25 \%$ no Sertão do Pajeú. O critério de localização para escolha das escolas foi determinado apenas pela coincidência com o local de trabalho dos estudantes participantes da pesquisa.

No decorrer da etapa de coleta de dados os estudantes participantes da pesquisa foram orientados a registrar suas observações acerca das práticas de gestão na escola onde trabalham, utilizando-se dos seguintes critérios: ser uma ação de gestão realizada pelo gestor, por sua equipe ou sob sua orientação. As ações deveriam ter relação direta com objetivos da escola pesquisada. Além disso, o registro deveria responder a questões básicas para compreensão dos objetivos amplos da ação, devendo informar: quem, como, o que, porque, onde e quando.

$\mathrm{Na}$ etapa seguinte, com base nos registros observados, o coordenador da pesquisa promoveu oficinas, com os estudantes pesquisadores, para análise dos dados. Coletivamente os registros foram analisados e identificados a partir de seu significado no contexto teórico da gestão escolar, utilizando-se para isso as seguintes subcategorias: fundamentos teóricos da gestão; dimensões de atuação da gestão (administrativa, burocrática, pedagógica e comunidade); natureza da ação da gestão (técnica ou política); público alvo direto da ação de gestão (professores, estudantes, comunidade, técnico); estratégia fortalecida pela ação (Conselho Escolar, PPP, Regimento escolar e/ou Comunidade).

\section{Dados e análise}




\section{CONFIGURAÇÕES DA GESTÃO ESCOLAR NOS SISTEMAS MUNICIPAIS E ESTADUAL EM PERNAMBUCO}

\section{LUIZ ALBERTO RIBEIRO RODRIGUES}

a) A influência da teoria da administração no modelo da gestão escolar atual

Historicamente no Brasil, o modelo teórico de gestão escolar carrega uma similaridade com a prática e os fundamentos administração de empresas, embasados pelo modelo de produção capitalista e referenciado pela teoria geral da administração a partir do pressuposto sobre a existência de semelhanças entre as organizações, que defende existir diferenças apenas relacionadas aos objetivos organizacionais. No caso da organização escolar, a diferença de gestão se localizaria nos métodos a adotar para garantir sua eficiência. VIII

Essa posição teórica sobre a generalidade entre as organizações corrobora, por outro lado, para a compreensão e crítica ao processo de gestão da escola na atualidade e a real influência histórica desses princípios e/ou dos fundamentos da teoria geral da administração. Nesse sentido, na literatura atual podem-se destacar ao menos quatro grandes teorias da ciência da administração em que espelham as práticas de gestão escolar: A teoria clássica, que enfatiza a prática do planejamento, da divisão do trabalho e do exercício de uma forte unidade de comando. Essa teoria, também conhecida como científica, pretendeu evitar desperdício, planejar, preparar e executar ações. Ela traduz assim, a tentativa de aplicar os métodos da ciência aos problemas da administração. ${ }^{\mathrm{IX}}$ A teoria burocrática, que enfatiza a formalidade na definição dos cargos, a impessoalidade nas relações, atos de gestão através de documentos e a necessidade de visualização de autoridades formais. ${ }^{\mathrm{X}}$ A teoria das relações humanas, que substituiu os conceitos da teoria científica e burocrática por "organização informal, motivação, incentivos sociais, dinâmica de grupo, comunicação, liderança, etc."XI Voltandose assim, para uma administração que busca integrar os objetivos das pessoas aos objetivos da instituição; e ainda a teoria crítica, que procura dar ênfase à relevância humana e a qualidade de vida com critério legitimador dos processos e das decisões da administração. XII

Com base nesses princípios, sucintamente aqui elencados, foram analisadas possíveis relações estabelecidas entre as ações de gestão observadas com as teorias mencionadas.

\begin{tabular}{|l|l|l|l|l|l|}
\hline Fundamento teórico da gestão & $\begin{array}{l}\text { Escolas } \\
\text { municipais }\end{array}$ & $\%$ & $\begin{array}{l}\text { Escolas } \\
\text { estaduais }\end{array}$ & $\%$ & $\%$ total \\
\hline Ênfase na teoria clássica Tarefas & 14 & 6,9 & 5 & 4,5 & 6,07 \\
\hline Ênfase em medidas Burocráticas & 84 & 41,4 & 65 & 59,1 & 47,6 \\
\hline Ênfase nas Relações humanas & 79 & 38,9 & 29 & 26,4 & 34,5 \\
\hline $\begin{array}{l}\text { Ênfase na teoria Crítica, na } \\
\text { qualidade de vida. }\end{array}$ & 26 & 12,8 & 11 & 10,0 & 11,82 \\
\hline & $\mathbf{2 0 3}$ & $\mathbf{1 0 0}$ & $\mathbf{1 1 0}$ & $\mathbf{1 0 0}$ & $\mathbf{1 0 0}$ \\
\hline
\end{tabular}

Quadro 1. Princípios da administração presente nas ações da gestão escolar.

No que se refere a gestão das escolas municipais, os índices indicam predominância de ações orientadas por princípios da administração burocrática com $41,4 \%$, seguido da teoria 


\section{CONFIGURAÇÕES DA GESTÃO ESCOLAR NOS SISTEMAS MUNICIPAIS E ESTADUAL EM PERNAMBUCO}

\section{LUIZ ALBERTO RIBEIRO RODRIGUES}

das relações humanas com $38,9 \%$, da teoria crítica com $12,8 \%$ e por fim, a teoria clássica com $6,9 \%$.

No âmbito das escolas estaduais, foram observadas que nas ações de gestão a maior predominância tem por base princípios da administração burocrática com 59,1\%, seguido da teoria das relações humanas com $26,4 \%$, da teoria crítica com $10 \%$ e por fim da teoria clássica com $4,5 \%$.

Como é possível observar, em ambas redes há um predomínio dos princípios da gestão burocrática, seguidas por aspectos afeitos à teoria das relações humanas. Um destaque porém ao caso da estadual, a acento ao princípio teórico burocrático é $17,7 \%$ ainda mais elevado, ou seja $59,1 \%$ das ações seguem esse princípio.

A princípio, não é de se estranhar que isso ocorra, se considerado que ações de gestão de natureza burocrática são próprias do ambiente público, dado o modo como os cargos são ocupados, em sua maioria por concurso público, de como a escola oficializa seus atos e como se comunica com os demais entes que compõem a rede, seja com a secretaria de educação, com instituições fornecedoras ou com outras entidades formadoras.

Nesse contexto, agir conforme princípios da teoria burocrática, significa por nas ações um alto grau de impessoalidade, de formalidade dos cargos e das funções, além de pensar soluções aos problemas da escola no âmbito da responsabilidade da gestão pública. Remeter muito da responsabilidade à Secretaria de Educação, como representativa do aparelho de gestão estatal, por exemplo, e nessa direção diminuir a importância da influência das pessoas nas decisões locais sobre a escola. Não significa somente gastar um maior tempo com os processos burocráticos, mas uma cultura que termina por enfatizar este princípio como a política da gestão. Há também um dado que a burocracia acaba favorecendo, o controle externo da escola, especialmente pelo governo. Assim, um tipo de gestão "[...] cada vez mais burocrática, permite ao Estado um controle maior da educação, para adequá-la ao projeto de desenvolvimento econômico do país, descaracterizando-a como atividade humana específica, submetendo-a a uma avaliação cujo critério é a produtividade, no sentido que lhe atribui a sociedade capitalista."XIII

$\mathrm{Na}$ trilha dessa análise, é possível inferir ainda que, os modos de gestão nas escolas municipais favorecem uma maior atenção às pessoas, aos processos motivacionais, $(38,9 \%) \mathrm{e}$ às ações apoiadas por critérios voltados à qualidade de vida daqueles que fazem a escolas $(12,8 \%)$. Considerando o fato de que a escola municipal pesquisada não tem um processo democrático de eleição de diretores, é possível que isso coloque a gestão em um contexto em que tenha que prestar contas, consultar, de modo a buscar permanentemente a legitimidade das ações de gestão. 


\section{CONFIGURAÇÕES DA GESTÃO ESCOLAR NOS SISTEMAS MUNICIPAIS E ESTADUAL EM PERNAMBUCO}

\section{LUIZ ALBERTO RIBEIRO RODRIGUES}

b) dimensões de atuação da gestão escolar (administrativa, burocrática, pedagógica e comunidade)

Um aspecto pertinente a compreensão da atuação da gestão escolar é a necessária consideração a sua natureza, ou seja, reconhecê-la como instituição educativa, diferenciada das demais organizações e do tradicional conceito de empresa capitalista. É nessa perspectiva que foi proposto uma análise da ação da gestão, observando-se sua relação com quatro sub dimensões a saber: administrativa, burocrática, pedagógica e comunidade. As duas primeiras, mais ligadas aos processos administrativos e as duas últimas ligada ao processo educativo, constitutivo essencial da função social da escola.

Existirá mesmo uma divisão das funções de gestão da escola? Talvez isso seja necessário como elemento didático para uma análise política. Considere-se que, na rede estadual em Pernambuco, o processo de escolha dos dirigentes escolares, ordenado em Decreto ${ }^{\text {XIV }}$ estabeleceu a diferenciação das funções do diretor e do diretor adjunto, sendo o primeiro responsável por questões de natureza administrativa e o segundo voltado a questões pedagógicas. Para o diretor, a responsabilidade recai sob o planejamento Estratégico, a liderança sobre a equipe, a comunicação e Integração com a Comunidade, a gestão dos recursos de apoio à Administração e ao Ensino e por fim a gestão administrativa e financeira da escola. Por outro lado, competem ao diretor adjunto, as funções de planejamento pedagógico, a orientação e o suporte pedagógico e, por fim, o acompanhamento e avaliação da aprendizagem. ${ }^{\mathrm{XV}}$

Vejamos o que diz a prática:

\begin{tabular}{|l|l|l|l|l|l|}
\hline Dimensões de atuação da gestão & $\begin{array}{l}\text { Escolas } \\
\text { municipais }\end{array}$ & $\%$ & $\begin{array}{l}\text { Escolas } \\
\text { estaduais }\end{array}$ & $\%$ & $\begin{array}{l}\% \\
\text { total }\end{array}$ \\
\hline Ação administrativa & 34 & 19,7 & 38 & 30,4 & $\mathbf{2 4 , 1 6}$ \\
\hline Ação burocrática & 20 & 11,6 & 15 & 12,0 & 11,74 \\
\hline Ação pedagógica & 74 & 42,8 & 59 & 47,2 & 44,63 \\
\hline Ação com a comunidade & 45 & 26,0 & 13 & 10,4 & 19,46 \\
\hline & 173 & 100 & 125 & 100 & 100 \\
\hline
\end{tabular}

Quadro 2. Dimensões de atuação da gestão.

A partir de uma leitura analítica dos dados acima, percebe-se que, no âmbito da gestão das escolas municipais, predominam a atuação voltada a questões pedagógicas, com 42,8\%, seguido de ações com a comunidade $26 \%$, ações administrativas com $19,7 \%$, e burocráticas com 11,6\%, Observe-se que, se somados as relações com a dimensão pedagógica às relativas a comunidade, pode-se concluir que $68,8 \%$, ou seja, quase dois terços da relação da gestão 


\section{CONFIGURAÇÕES DA GESTÃO ESCOLAR NOS SISTEMAS MUNICIPAIS E ESTADUAL EM PERNAMBUCO}

\section{LUIZ ALBERTO RIBEIRO RODRIGUES}

escolar municipal estão voltada à questões de ordem pedagógica e de relações com a comunidade. Apenas um terço está relacionada às questões de ordem administrativas e burocráticas.

A proximidade com a comunidade, no caso das escolas municipais, pode estar associada a modalidade de escolha dos gestores das escolas municipais. Com a ausência de uma regulamentação da gestão democrática, a função de gestor escolar é, em quase totalidade dos municípios, objeto de indicação do político local. Nesta região, apenas o município de Vicência tem eleições diretas, o que deixa o gestor vulnerável quanto a sua legitimidade democrática.

Registra-se por outro lado, que os dados observados na gestão da escola estadual indicam ser ainda mais acentuada a relação da gestão com ações de ordem pedagógica, 47,2\%, seguido de ações administrativas 30,4\%. Neste último item, se somado aos $12 \%$ da relação com as questões burocráticas, pode-se concluir que $42,4 \%$ das ações de gestão têm uma relação indireta com o aspecto central da educação, a prática pedagógica e ainda a uma baixa relação da gestão com a comunidade, $10,4 \%$.

Pode-se observar que a gestão da escola municipal atribui maior atenção $(42,8 \%)$ aos aspectos pedagógicos e $26 \%$ à comunidade, totalizando $68.8 \%$, maior que contra $57,6 \%$ da escola estadual para os mesmos itens.

c) Natureza da ação da gestão (técnica ou política)

$\mathrm{Na}$ perspectiva do que vem sendo aqui abordado, a essência da atuação da gestão escolar, de sua liderança, da equipe, do colegiado, passa necessariamente pela expectativa política pedagógica que se pode vir a construir. Discutir o processo pedagógico, pensar permanentemente a organização do ambiente educativo, planejar o detalhamento do planejamento pedagógico de forma colegiada essa é função central.

Por outro lado, não há dúvidas que se exige da gestão outro tipo de atuação e competência, a técnica. Isso passa pelo efetivo domínio de instrumentos de comunicação interinstitucional, da regulamentação e dos fundamentos legais da educação, da compreensão de funções básicas de gestão, tais como a elaboração do planejamento, do processo de controle, da supervisão e da avaliação entre outros. Some-se a isso conhecimento sobre princípios da gestão pública, habilidades técnicas para gerir recursos financeiros, habilidades para lidar com relações interpessoais, entre outros.

É certo pensar que, todas essas competências de natureza técnica, não tem um fim em si mesmo, mas ganham sentido quando estão a serviço da gestão e dos processos políticos pedagógicos. 


\section{CONFIGURAÇÕES DA GESTÃO ESCOLAR NOS SISTEMAS MUNICIPAIS E ESTADUAL EM PERNAMBUCO}

\section{LUIZ ALBERTO RIBEIRO RODRIGUES}

Seguem os dados observados:

\begin{tabular}{|l|l|l|l|l|l|}
\hline Natureza da ação de gestão & $\begin{array}{l}\text { Escolas } \\
\text { municipais }\end{array}$ & $\%$ & $\begin{array}{l}\text { Escolas } \\
\text { estaduais }\end{array}$ & $\%$ & $\begin{array}{l}\% \\
\text { total }\end{array}$ \\
\hline Ação de natureza técnica & 60 & 34,9 & 73 & 77,7 & 50 \\
\hline Ação de natureza política & 112 & 65,1 & 21 & 22,3 & 50 \\
\hline & 172 & 100 & 94 & 172 & 100 \\
\hline
\end{tabular}

Quadro 3. Natureza da ação de gestão.

Como se pode observar, nas ações de gestão na rede municipal há uma predominância sobre uma atuação de natureza política, $65,1 \%$, seguido de $34,9 \%$ de ações de natureza técnica. Diferentemente, no âmbito estadual, a ênfase encontra-se nas questões de ordem técnica, com $77,7 \%$, contra $22,3 \%$ de ações relacionadas à dimensão política.

Esse quadro indica que há uma distinção entre as práticas de gestão das escolas nos municípios, com atuação mais política, em relação à rede estadual que apresenta uma atuação pautada em questões de natureza técnica.

No âmbito dos municípios pesquisados, o acento às ações de natureza política pode receber, de algum modo, influência do fator escolha dos dirigentes, como mencionado no item anterior, somado ao fato de que as escolas municipais oferecem o ensino fundamental I, etapa formativa em que a incidência de políticas de financiamento externo é menor. No caso das escolas estaduais, com foco em questões de natureza técnica, dever-se considerar que nela há uma predominância da oferta do ensino fundamental II e do ensino médio, etapas em que há uma maior incidência de ações financiadas pelo MEC, ações essas que acabam por ocupar um tempo maior da gestão à realização de procedimentos técnicos/burocráticos.

d) Público alvo direto da ação de gestão (professores, estudantes, comunidade, técnico)

A literatura atual ressalta que, no processo de gestão escolar, considerando o princípio básico da participação, a relação da gestão com professor, estudante, técnico e comunidade tem diferentes e significativas funções, sobretudo porque envolvem em diferentes perspectivas a essência da instituição escolar, o processo do aprender. Mas afinal, o que aprendem cada uma desses? 


\section{CONFIGURAÇÕES DA GESTÃO ESCOLAR NOS SISTEMAS MUNICIPAIS E ESTADUAL EM PERNAMBUCO}

\section{LUIZ ALBERTO RIBEIRO RODRIGUES}

Conforme Hora, ${ }^{\mathrm{XVI}}$ o processo participativo é um aprofundamento contínuo para todos. Em particular para a comunidade, na medida em que ela pode contribuir com o debate sobre a questão educacional, seus propósitos, traçando objetivos, dando sentido ao saber e ao modo como ele é construído.

Os demais grupos, intrínsecos às escolas, detém razões da mesma forma significativas na relação com a gestão colegiada. Os professores, na medida em que buscam uma melhor relação entre o conhecimento e a realidade da sociedade onde está inserida a escola. No desafio permanente de ser facilitador do processo do aprender e por isso sente-se mobilizados por ações de gestão para tornar os conhecimentos presentes na vida dos estudantes, a partir de experiências no exercício de funções políticas que podem vir a desenvolver nas assembleias e no conselho escolar. Os técnicos, na medida em que desenvolvem a compreensão acerca do sentido da sua atividade de apoio ao conjunto das ações pedagógicas.

Seguem os dados observados:

\begin{tabular}{|l|l|l|l|l|l|}
\hline $\begin{array}{l}\text { Público alvo direto da ação de } \\
\text { gestão }\end{array}$ & $\begin{array}{l}\text { Escolas } \\
\text { municipa } \\
\text { is }\end{array}$ & $\%$ & $\begin{array}{l}\text { Escolas } \\
\text { estaduais }\end{array}$ & $\%$ & $\%$ total \\
\hline Professores & 113 & 38,6 & 49 & 37,7 & 38,3 \\
\hline Estudantes & 42 & 14,3 & 53 & 40,8 & 22,46 \\
\hline Comunidade & 65 & 22,2 & 14 & 10,8 & 18,68 \\
\hline Técnico & 73 & 24,9 & 14 & 10,8 & 20,57 \\
\hline & 293 & 100 & 130 & 100 & 100 \\
\hline
\end{tabular}

Quadro 4. Público alvo direto da ação de gestão

Os acima indicam que no âmbito das escolas municipais, o grupo que mais se relaciona com a gestão é o de professor, com $38,6 \%$, seguido por técnico com $24,9 \%$, o da comunidade com $22,2 \%$, e, por fim, os estudantes com $14,3 \%$.

$\mathrm{Na}$ gestão das escolas estaduais, foi observado uma maior relação com os estudantes, $40,8 \%$, seguido por professores com $37,7 \%$, e, no mesmo nível, a comunidade e os técnicos, $10,8 \%$ cada.

Como se observa, o grupo que mais se relaciona com a gestão da escola estadual são os estudantes. Se considerados ambas as redes de ensino, as relações estão centradas no professor. A relação com a comunidade e com técnicos se dão na mesma proporção em ambas às redes, $22,2 \%$ e $24 \%$ na rede municipal e 10,8\% para ambos os grupos na rede estadual. Em ambas as redes a relação com a comunidade é pouco significativa, configurando apenas $18,68 \%$.

Mas afinal, o que isso pode significar? Para os objetivos da escola, para o processo do aprender, tem ou não significado a relação da gestão com a comunidade? Pode ser que essa seja uma descoberta para alguns educadores: É na comunidade que os objetivos educacionais ganham sentido e, como referem Christensen, Horn e Johnson, ${ }^{2}$ dar sentido, mobilizar estudantes para aprender, por esses objetivos, por dar essa direção, as escolas não podem ser 


\section{CONFIGURAÇÕES DA GESTÃO ESCOLAR NOS SISTEMAS MUNICIPAIS E ESTADUAL EM PERNAMBUCO}

\section{LUIZ ALBERTO RIBEIRO RODRIGUES}

encarregadas sozinhas. De outro modo, dar sentido aos objetivos educacionais é uma responsabilidade da sociedade.

É comum delegar as escolas uma larga gama de objetivos, tais como "maximizar o potencial humano; viabilizar uma democracia participativa, vibrante [...]; aperfeiçoar as habilidades, capacidade e atitudes [...]; fortalecer o entendimento de que as pessoas podem ver as coisas de maneira diferente umas das outras - e de que essas diferenças merecem respeito, jamais perseguição [...]."XVIII Afirmam esses autores, que as escolas precisam da sociedade para construir esses significados, "as escolas precisam constituir uma força significativa, positiva, nessa direção e elas podem certamente melhorar."XIX . Esse é certamente o maior aprendizado que a comunidade pode construir na sua relação com a escola.

Tornar a comunidade o público alvo direto da ação de gestão é uma ação política a ser enfrentada pelos gestores. É sem dúvida um novo caminho a ser repensado, em função do papel social da escola, ser da comunidade, instrumento estratégico da cultura.

Mais do que uma decisão burocrática, essa é uma escolha política. É necessário considerar que as relações que a gestão escolar estabelece ou deixa de estabelecer através de suas ações concretas, são resultantes de opções que a escola faz ao longo de sua história.

e) Estratégia fortalecida na ação (Conselho Escolar, PPP, Regimento escolar, Comunidade).

Vamos aos dados observados:

\begin{tabular}{|l|l|l|l|l|l|}
\hline $\begin{array}{l}\text { Estratégica de gestão } \\
\text { fortalecida pela ação. }\end{array}$ & $\begin{array}{l}\text { Escolas } \\
\text { municipais }\end{array}$ & $\%$ & $\begin{array}{l}\text { Escolas } \\
\text { estaduais }\end{array}$ & $\%$ & $\begin{array}{l}\% \\
\text { total }\end{array}$ \\
\hline Conselho escolar & 9 & 4,8 & 4 & 4,9 & 4,815 \\
\hline Projeto Político Pedagógico & 71 & 37,6 & 31 & 38,3 & 37,78 \\
\hline Regimento & 58 & 30,7 & 29 & 35,8 & 32,22 \\
\hline Comunidade & 51 & 27,0 & 17 & 21,0 & 25,19 \\
\hline & 189 & 100 & 81 & 100 & 100 \\
\hline
\end{tabular}

Quadro 5. Estratégica de gestão fortalecida pela ação.

Os dados do quadro acima indicam que as mais importantes estratégias de gestão na rede municipal são o Projeto Político Pedagógico, 37,6\%, o regimento com 30,7\%, seguido pela comunidade com $27 \%$ e por fim o conselho escolar com $4,8 \%$ das ações de gestão.

A mesma lógica é seguida na rede estadual, afirmando a importância que se dá a partir do Projeto Político Pedagógico, 38,3\%, do regimento com 35,8\%, seguido da comunidade com $21 \%$ e do conselho escolar com $4,9 \%$. 


\section{CONFIGURAÇÕES DA GESTÃO ESCOLAR NOS SISTEMAS MUNICIPAIS E ESTADUAL EM PERNAMBUCO}

\section{LUIZ ALBERTO RIBEIRO RODRIGUES}

A centralidade atribuída à estratégia do Projeto Político Pedagógico estar mesmo garantida a partir desses dados? O PPP garante a existência de uma prática de planejamento em que as ações sejam resultantes da compreensão coletiva, do pensar as atividades pedagógicas de modo consciente?

Por esses dados não é possível afirmar isso. Ao contrário, considerando essas informações, pode-se observar que o grupo natural para a prática do planejamento escolar, o conselho, não tem relevância sob o aspecto estratégico da gestão escolar nas redes municipal e estadual. $\mathrm{O}$ conselho escolar aparece apenas $4,81 \%$ das ações observadas em ambas às redes de ensino.

De onde se origina então essa atenção tão elevada ao PPP? Ela tem relação com a modalidade de planejamento estratégico na escola, o PDE escola? Sem dúvida, o aprofundamento da política do PDE nas duas últimas duas décadas, fez a escola dar maior atenção ao PPP. Ele tornou-se o documento balizador das ações, sobretudo por exigência burocrática para os processos de financiamento e formação continuada.

Deve-se considerar ainda que, as políticas de gestão advindas da reforma da educação mencionadas na introdução deste texto, fundamentadas no gerencialismo político, venderam uma falsa ideia acerca de uma possível autonomia dos estados, municípios e das escolas, a partir do planejamento "para que possam captar mais recursos na fonte." XX

Ao invés de fortalecer o princípio político da autonomia, conforme o preceito legal citado no início deste estudo, o foco no planejamento com estratégia de gestão da escola "[..] sobretudo, tem como objetivo a retirada do Estado das funções mantenedoras, resguardando a este a função supletiva e distributiva do setor."XXI

A citada autora chama a atenção de que há uma questão de fundo que sustenta as metodologias do planejamento estratégico na escola, a definição do mínimo de investimento.

[...] o planejamento central parece não responder mais às expectativas do momento. Ao contrário, as metodologias de planejamento agora devem balizar-se na realidade local, de cada escola. [...] o debate atual gira em torno de um mínimo de investimentos, mas cada escola, cada município, cada estado, gestará sua política de acordo com suas potencialidades. ${ }^{\text {XII }}$

É nesse sentido que o planejamento aparece como estratégia principal e o instrumento da gestão dentro da política gerencialista que está presente na política educacional na atualidade e financia diversas ações, por meio do Programa Dinheiro Direto na Escola PDDE. 


\title{
CONFIGURAÇÕES DA GESTÃO ESCOLAR NOS SISTEMAS MUNICIPAIS E ESTADUAL EM PERNAMBUCO
}

\author{
LUIZ ALBERTO RIBEIRO RODRIGUES
}

Por outro lado, não se pode perder de vista que, como função de gestão, o planejamento é sim uma valiosa estratégia política para pensar o futuro, a partir de diferentes valores, anseios, óticas. É a estratégia para se estabelecer e reformular as políticas com autores e executores. Afinal, a democracia não ocorre espontaneamente, precisa ser provocada. ${ }^{\text {XXIII }}$

\section{Conclusão}

Este estudo pretendeu caracterizar a concepção e práticas da gestão escolar presentes nos sistemas municipais e estadual de educação em Pernambuco. Considerou-se que, na atualidade, as políticas educacionais impulsionam as escolas públicas a realizarem processos de gestão nos moldes das organizações privadas, que acaba por fortalecer ainda mais o controle burocrático do estado sob às escolas. Com base no estudo relatado até então, pode-se inferir as seguintes conclusões:

a) A gestão escolar estadual está fortemente marcada por princípios da administração burocrática. Isso significa que as ações de gestão são realizadas com um alto grau de impessoalidade, de formalidade dos cargos e das funções, além de que a busca de soluções aos problemas da escola tende à serem remetidos ao âmbito da alta gestão do órgão público, no caso, à Secretaria de Educação, diminuindo assim a importância da influência das pessoas nas decisões sobre os rumos da escola.

No caso da escola municipal, foi percebido uma forte aproximação aos princípios das relações humanas, possivelmente, resultado do esforço do gestor em garantir permanentemente alguma forma de legitimidade junto à comunidade escolar, dado que o cargo que ocupa é indicação do Prefeito e não eleição entre os pares. Assim, a atenção as pessoas pode não significar valorização do princípio da participação e da autonomia como prática política, por vezes, como estratégia para legitimar o cargo de confiança e/ou mesmo favorecer o político que a indicou.

a) Há significativa aproximação da gestão escolar municipal e estadual à questões de ordem pedagógica. No entanto, nas escolas municipais, apenas um terço estão relacionadas à questão administrativa e burocrática, enquanto que na gestão estadual, a relação das ações de gestão com os aspectos administrativos é superior à rede municipal em quase $11 \%$.

b) A atuação da gestão na rede municipal é predominantemente política. Diferentemente, no âmbito estadual, a ênfase encontra-se nas questões de ordem técnica. 


\section{CONFIGURAÇÕES DA GESTÃO ESCOLAR NOS SISTEMAS MUNICIPAIS E ESTADUAL EM PERNAMBUCO}

\section{LUIZ ALBERTO RIBEIRO RODRIGUES}

c) Em ambas as redes de ensino, as relações da gestão estão centradas no professor. É pouco significativa a relação da gestão com os técnicos e ainda menor com a comunidade. Os estudantes têm maior atenção na gestão estadual.

d) As principais estratégias de gestão fortalecidas nas ações observadas são o Projeto Político Pedagógico e o Regimento. Em ambas as redes há pouca atenção ao Conselho Escolar, o que descaracteriza a gestão colegiada e o sentido do PPP.

A combinação dos dados aqui apresentado permite compreender a seguinte configuração da gestão escolar: No âmbito da rede municipal, caracteriza-se por princípios das relações humanas, com atenção aos aspectos pedagógicos, com atuação política, centrada no professor, com pouca relação com a comunidade. A estratégia principal de gestão está centrada no PPP e no Regimento, com pouca atenção a gestão colegiada.

Por outro lado a gestão escolar estadual é fortemente burocrática, com atenção aos aspectos pedagógicos, ocupada com questões administrativas de natureza técnica, centrada no professor, com pouca relação com a comunidade. A estratégia principal é fortalecer o PPP e o Regimento, com pouca atenção a gestão colegiada, especialmente desvinculada da participação do conselho escolar.

Deve-se considerar que na rede estadual em Pernambuco, nos últimos oito anos, houve um avanço significativo na educação como um todo e especialmente na gestão educacional, tais como uma regulamentação mínima para a escolha dos dirigentes, a institucionalização dos conselhos, uma política de organização burocrática e de controle administrativa definida. $\mathrm{Na}$ gestão escolar municipal, por outro lado, as políticas de financiamento do MEC, impulsionou o planejamento estratégico e gestão financeira dos recursos, somado ainda aos traços apresentados pela pesquisa, em que se observou a proximidade da gestão com as pessoas professores e comunidade, somado ao baixo nível de regulação municipal.

Fica ainda o desafio de garantir, em ambos os casos, a materialização dos princípios básicos à gestão democrática, como a participação e a autonomia. Nesse sentido, reduzir os efeitos da regulação e do controle externo veiculados pelas políticas e suas ações financiadas, de modo a tornar a comunidade o público alvo direto da ação de gestão é uma ação política a ser enfrentada pelos gestores. Esse é, sem dúvida, um caminho a ser trilhado pela gestão escolar, pela valorização política do Conselho Escolar, de modo a tornar a Escola uma instituição educativa da comunidade, um instrumento estratégico da cultura e da formação política. Mais do que uma decisão burocrática, essa é uma escolha política a ser gestada nos colegiados. Afinal, o exercício da autoridade é resultado de vários fatores, entre os quais a competência, a imaginação, a sensibilidade, a postura crítica - individual e/ou coletiva, e o sentimento político de solidariedade.

Novos estudos ainda são necessários para acompanhar e analisar as novas configurações da gestão escolar, sobretudo a partir do cenário que aponta principalmente o Plano Nacional de Educação, a perspectiva de institucionalização de um Sistema Nacional de 


\title{
CONFIGURAÇÕES DA GESTÃO ESCOLAR NOS SISTEMAS MUNICIPAIS E ESTADUAL \\ EM PERNAMBUCO
}

\section{LUIZ ALBERTO RIBEIRO RODRIGUES}

Educação, a regulamentação, pelo Conselho Nacional de Educação, da gestão escolar democrática, entre outros.

\section{Notas}

\begin{abstract}
' Doutor em Educação pela UFPE (2009). Professor Adjunto da Universidade de Pernambuco, Vice-coordenador do Programa de Mestrado Profissional em Educação da UPE, pesquisador da área de gestão e políticas públicas em educação e formação de professores.
\end{abstract}

II BRASIL/MEC. Lei de Diretrizes e Bases da Educação Nacional. 1996. Disponível em: http://portal.mec.gov.br/arquivos/pdf/ldb.pdf. Acessado em: 20 de junho de 2015a.

${ }^{\mathrm{III}}$ BRASIL. Plano Nacional de Educação. Lei no 13.005, de 25 de junho de 2014. Brasília, 2014. Disponível em: http://www.planalto.gov.br/ccivil_03/_ato2011-2014/2014/lei/113005.htm. Acessado em 15 de junho de 2015

${ }^{\text {IV }}$ HORA, Dinar Leal da. Gestão Democrática na escola. 15 ed; Papirus, S.P., Campinas, 2009.

${ }^{\mathrm{V}}$ RODRIGUES, L. A. R. R. Políticas de Gestão Escolar: uma análise do plano de desenvolvimento da escola na região da mata norte de Pernambuco (1999- 2007). Editora Edupe. Recife, 2013

${ }^{V I}$ OLIVEIRA, Dalila Andrade. Educação e Planejamento: A escola como núcleo da gestão. In: (org). Gestão Democrática da Educação. Desafios contemporâneos. $5^{\text {a }}$ edição. Ed. Vozes, Petrópolis, 2003. P. 9

VII Ibidem. P. 95

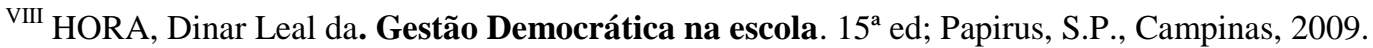

${ }^{\text {Ix }}$ CHIAVEnATO, Idalberto. Administração -Teoria, Processo e Prática. $3^{a}$ edição. Makron Books, 2000

${ }^{\mathrm{x}}$ Ibidem

${ }^{\mathrm{XI}}$ Ibidem. P. 20

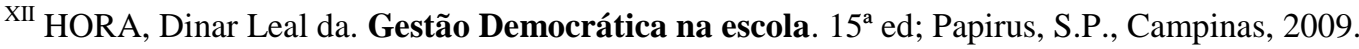

XIII Ibidem. P.46

${ }^{\mathrm{XIV}}$ PERNAMBUCO. Governador do Estado. DECRETO No 38.103, DE 25 DE ABRIL DE 2012.

Regulamenta os critérios e procedimentos para realização de processo de seleção para função de representação de diretor escolar e diretor adjunto das escolas estaduais, e das outras providências. Recife, 2012. Disponível em https://www.google.com.br/search?sourceid=chrome-

psyapi2\&rlz=1C1CAFA_enBR625BR625\&ion=1\&espv=2\&ie=UTF-

$8 \& \mathrm{q}=$ Decreto $\% 2038.103 \% 20 \mathrm{de} \% 2025 \% 20 \mathrm{de} \% 20$ abril\%20de $\% 202012 \&$ oq=Decreto $\% 2038.103 \% 20 \mathrm{de} \% 2025 \%$ 20de\%20abril\%20de\%202012\&aqs=chrome..69i57j0.1459j0j7. Acessado em 20 de abril de 2015.

xv Ibidem. 


\section{CONFIGURAÇÕES DA GESTÃO ESCOLAR NOS SISTEMAS MUNICIPAIS E ESTADUAL \\ EM PERNAMBUCO}

LUIZ ALBERTO RIBEIRO RODRIGUES

\footnotetext{
${ }^{\text {XVI }}$ HORA, Dinar Leal da. Gestão Democrática na escola. 15ª ed; Papirus, S.P., Campinas, 2009.

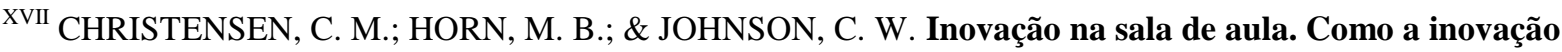
disruptiva muda a forma de aprender. Tradução: Rodrigo Sardenberg Bookman, 2012

XVIII Ibidem. P. XVI

XIX Ibidem. P XXII

XX OLIVEIRA, Dalila Andrade. Educação e Planejamento: A escola como núcleo da gestão. In: (org).

Gestão Democrática da Educação. Desafios contemporâneos. 5ª edição. Ed. Vozes, Petrópolis, 2003

XXI Ibidem. P. 97

XXII Ibidem.

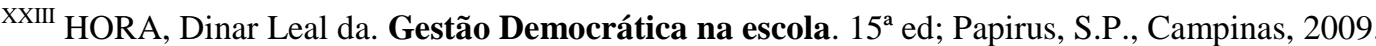

\section{REFERÊNCIAS}

BRASIL. Plano Nacional de Educação. Lei no 13.005, de 25 de junho de 2014. Brasília, 2014. Disponível em: http://www.planalto.gov.br/ccivil_03/_ato20112014/2014/lei/113005.htm. Acessado em 15 de junho de 2015.

BRASIL/MEC. Lei de Diretrizes e Bases da Educação Nacional. 1996. Disponível em: http://portal.mec.gov.br/arquivos/pdf/ldb.pdf. Acessado em: 20 de junho de 2015a.

CHIAVEnAtO, Idalberto. Administração -Teoria, Processo e Prática. $3^{a}$ edição. Makron Books, 2000.

CHRISTENSEN, C. M.; HORN, M. B.; \& JOHNSON, C. W. Inovação na sala de aula. Como a inovação disruptiva muda a forma de aprender. Tradução: Rodrigo Sardenberg Bookman, 2012.

FERREIRA, Naura S. C. (org). Gestão democrática da educação: atuais tendências, novos desafios. $3^{\text {a }}$ edicação. Ed. Cortez, São Paulo, 2001.

HORA, Dinar Leal da. Gestão Democrática na escola. $15^{\mathrm{a}}$ ed; Papirus, S.P., Campinas, 2009.

OLIVEIRA, Dalila Andrade. Educação e Planejamento: A escola como núcleo da gestão. In: (org). Gestão Democrática da Educação. Desafios contemporâneos. $5^{\text {a }}$ edição. Ed.

Vozes, Petrópolis, 2003. 
PERNAMBUCO. Governador do Estado. DECRETO No 38.103, DE 25 DE ABRIL DE 2012. Regulamenta os critérios e procedimentos para realização de processo de seleção para função de representação de diretor escolar e diretor adjunto das escolas estaduais, e das outras providências. $\quad$ Recife, $2012 . \quad$ Disponível em https://www.google.com.br/search?sourceid=chromepsyapi2\&rlz=1C1CAFA enBR625BR625\&ion=1\&espv=2\&ie=UTF8\&q=Decreto $\% 2038.103 \% 20 \mathrm{de} \% 2025 \% 20 \mathrm{de} \% 20 \mathrm{abri1} \% 20 \mathrm{de} \% 202012 \&$ oq=Decreto $\% 2038$. $103 \% 20 \mathrm{de} \% 2025 \% 20 \mathrm{de} \% 20 \mathrm{abri1} \% 20 \mathrm{de} \% 202012 \& \mathrm{aqs}=$ chrome..69i57j0.1459j0j7. Acessado em 20 de abril de 2015.

PERNAMBUCO. Nome da Corte ou Tribunal./ Lei ou Decreto, $\mathrm{n}^{\circ}$, data (dia mês ano)./ Ementa./ Indicação de publicação oficial (título, / local, / volume, / número, dia / mês / ano. / Seção, / parte -se houver). Disponível em: . /Acesso em: dia / mês abreviado/ ano.

RODRIGUES, L. A. R. R. Políticas de Gestão Escolar: uma análise do plano de desenvolvimento da escola na região da mata norte de Pernambuco (1999- 2007). Editora Edupe. Recife, 2013. 